Article

\title{
High-Precision Monitoring of Average Molecular Weight of Polyethylene Wax from Waste High-Density Polyethylene
}

\author{
Zhouchao Guo, Xia Lan and Ping Xue * \\ School of Mechanical and Electrical Engineering, Beijing University of Chemical Technology, Beijing 100029, \\ China; gzctaopu@yeah.net (Z.G.); lanxia@mail.buct.edu.cn (X.L.) \\ * Correspondence: xueping@mail.buct.edu.cn
}

Received: 14 September 2019; Accepted: 5 January 2020; Published: 10 January 2020

\begin{abstract}
High-density polyethylene (HDPE) is a major component of polyethylene waste, yet only under $29.9 \%$ of waste HDPE is recycled. As an important additive, polyethylene wax (PEW) is increasingly used in many industries such as plastics, dyes, and paints. The preparation of PEW has received considerable interest because recycling and precisely controllable production can bring huge economic benefits. In this study, to recycle waste HDPE, a single screw extruder was innovatively combined with a connecting pipe to prepare PEW from the pyrolysis of waste HDPE. Using a test platform, PEWs were prepared under different pyrolysis temperatures and screw speeds, and corresponding number-average molecular weights (NAMWs) of PEWs were measured. To precisely monitor NAMW of PEW, a program was developed in MATLAB. First, the relationship between NAMW and pyrolysis ratio was obtained, and a measure-point-independence verification was conducted. Then, modified Arrhenius equations and time-dependent pyrolysis temperature were for the first time introduced into the HDPE pyrolysis model. Furthermore, the screw-speed-dependent inverse method was proposed and validated for high-precision monitoring of NAMW of PEW from the pyrolysis of waste HDPE by extrusion. PEW of desired molecular weight was able to be precisely obtained from waste HDPE.
\end{abstract}

Keywords: high-precision monitoring; polyethylene wax; HDPE pyrolysis; extrusion

\section{Introduction}

Polyethylene (PE) materials have become more and more important to everyday life, being used in a wide scope of applications from pipe to packaging to fiber. However, with their increasing use, PE waste makes up a large proportion of all municipal solid waste, yet only a small proportion of PE waste is recycled. High-density polyethylene (HDPE) is a major component of PE waste, yet only under $29.9 \%$ of waste HDPE is recycled [1]. Thus, developing effective reusing techniques for HDPE waste is important.

Although the volume of waste HDPE materials can be mitigated by waste minimization [2] and mechanical recycling [3], large-scale solutions are required for the large magnitude of waste HDPE materials [4]. Among the solutions available for a large-scale recycling of waste HDPE, are stand out pyrolysis and gasification [5,6]. Gasification technologies have a long history of research [7], and the gasification of heterogeneous mixtures of waste PE has been realized [8]. However, compared to gasification, pyrolysis requires lower energy and produces lower amounts of pollutants because it operates at lower temperature and generates less $\mathrm{CO}_{2}$ [9]. In addition, the pyrolysis technology can be used to produce functional waxes or monomer materials with appropriate reaction equipment and operating conditions [10]. Using a system of fixed bed-fixed bed reactors, Akubo and coworkers 
obtained aromatic fuel oils from HDPE pyrolysis [11]. As an important additive, polyethylene wax (PEW) is increasingly used in many industries such as plastics, dyes, and paints. PEW of appropriate molecular weight can be used as a release agent in plastic processing.

Pyrolysis, heating the material under non-oxidative condition, is an attractive waste recycling method because of its simplicity and ability to reprocess heterogeneous waste [12,13]. However, inhomogeneous heating can occur in existing equipment of PE pyrolysis, such as kettle type [14] or tube type [15]. The properties of pyrolysis products can be affected for the reason that inhomogeneous heating can induce hot spots, excessive pyrolysis, and even carbon deposition of PEW. In such cases, single screw extruder (SSE) is considered as a new and effective method to continuously prepare PEW with comparatively homogeneous heating [16]. However, a greater understanding of the mechanism of HDPE pyrolysis and a precise monitoring of molecular weight of PEW are needed to continue the development of this important technology.

The high molecular weight and polydispersity of HDPE cause its pyrolysis reaction network to often involve hundreds of species and reactions. The complex reaction network often gives rise to a broad product spectrum [17]. This complexity of the pyrolysis reactions makes it difficult to use experimental methods to obtain detailed mechanistic insight. In this situation, creating a mathematical model is a useful tool for obtaining insight into the complex mechanism of HDPE pyrolysis. PE pyrolysis has been studied for a long history [18-20]; however, unresolved questions surrounding the mechanism and kinetics still exist, most likely resulting from the difficulty in analyzing the diverse product spectrum [21]. The competition between inter- and intra-molecular hydrogen transfer reactions has attracted a variety of studies [22-25]; however, their conclusions about the relative importance of the two reaction modes are inconsistent.

In general, there are three reaction pathways for polymer pyrolysis: (1) Unzipping, which yields monomer from the polymer; (2) backbiting (BB), which yields a series of low molecular weight products; and (3) random scission (RS), which yields a diverse array of low molecular weight products [26]. The biggest difference between BB and RS pathways is just the competition between inter- and intra-molecular hydrogen transfer reactions. Since an equally stable secondary carbon radical generates for every mid-chain hydrogen, PE is especially susceptible to both BB and RS pathways. Faravelli and coworkers developed a series of versions of a mechanistic model for PE pyrolysis [27-29]. Their initial model, focusing on the total product yield, only included the RS pathway [27]. They improved this model with the addition of the BB pathway so that detailed product distributions were able to be modeled [28]. With the competition between RS and BB analyzed in their most recent modeling work, they found that RS was more important in PE pyrolysis [29]. Levine and Broadbelt developed a detailed mechanistic model for HDPE pyrolysis, allowing the tracking of specific products during the pyrolysis procedure of HDPE [30]. Likewise, continuous improvements have been done in the treatment of landfill waste plastics by means of an artificial neural network [31] and a multiple linear regression model [32]. However, the modified Arrhenius equation and time-dependent pyrolysis temperature are rarely reported in the literature. The method of monitoring number-average molecular weight (NAMW) of PEW from available observations of pyrolysis temperature and screw speed is new. In addition, an inverse method is rarely used to estimate NAMW of PEW, and high-precision monitoring of NAMW of PEW from the pyrolysis of waste HDPE by extrusion is new.

In this study, to recycle waste HDPE, a single screw extruder was innovatively combined with a connecting pipe to prepare PEW from the pyrolysis of waste HDPE. Using a test platform, PEWs were prepared under different pyrolysis temperatures and screw speeds, and corresponding NAMWs of PEWs were measured. To monitor NAMW of PEW, a program was developed in MATLAB. First, the relationship between NAMW and pyrolysis ratio was obtained based on RS reaction pathway, and measure-point-independence verification was added into the program. Then, the modified Arrhenius equation and time-dependent pyrolysis temperature were for the first time introduced into the HDPE pyrolysis model for a higher monitoring precision. Furthermore, the inverse method 
with screw-speed-dependent reaction rate constant was proposed and validated for high-precision monitoring of NAMW of PEW from the pyrolysis of waste HDPE by extrusion.

\section{Test Procedure}

\subsection{Test Platform}

Using a test platform, PEW was prepared from the pyrolysis of waste HDPE in a single screw extruder (SSE) and a connecting pipe. A flowchart of the test platform is shown in Figure 1. It can be seen that waste HDPE from a feed hopper flows through a SSE and a connecting pipe, and then flows into a cooling tank. There are four heating zones (Zone \#1, \#2,\#3, and \#4) for the SSE and two heating zones (Zone \#5 and \#6) for the connecting pipe. HDPE is pyrolyzed in the SSE and the connecting pipe, while PEW is cooled and stored in the cooling tank.

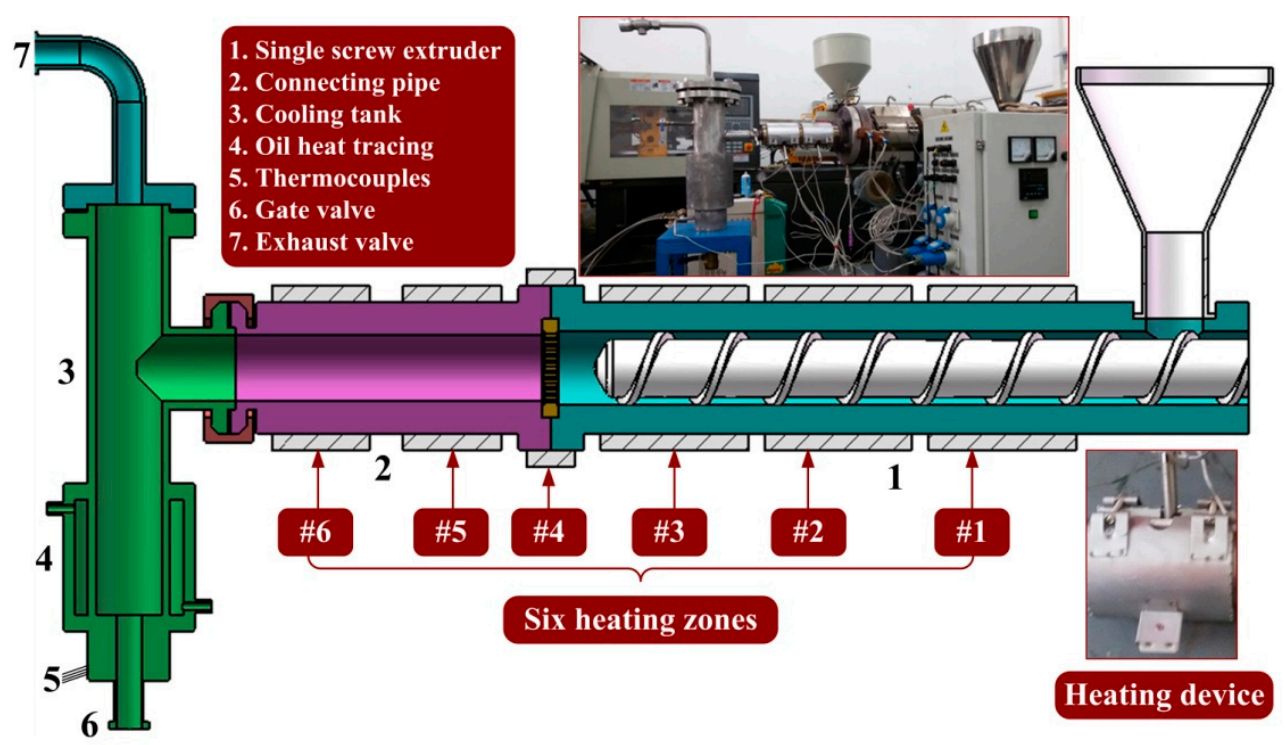

Figure 1. Flowchart of test platform.

To guarantee a continuous pyrolysis of HDPE in the SSE, the pressure in the cooling tank should not be too high. Generated gas during the pyrolysis of HDPE flows from a top discharge of the cooling tank, passes through an exhaust valve, and finally flows into a device for tail gas treatment. The exhaust valve should be a check valve in case air flows into the cooling tank and PEW of high temperature oxidizes or even spontaneously combusts. In addition, there is a metallic pressure sealing ring between the connecting pipe and the cooling tank, which also guarantees the inert condition (i.e., absence of oxygen). On the outer surface of the cooling tank, we use a sleeve in which conduction oil with high temperature flows to avoid the clot of liquid PEW. In addition, thermocouples and data acquisition unit are used to measure the temperature of PEW at the bottom outlet of the cooling tank.

\subsection{Preparation of Polyethylene Wax}

HDPE (ME9180), of which the number-average molecular weight is 13,295, is provided by LG Co. (Seoul, Korea). The heating temperatures of the SSE and the connecting pipe under four cases are shown in Figure 2, while the temperature of the oil heat tracing is set as $160^{\circ} \mathrm{C}$. The screw speed of the SSE is set as 2, 10, 20, 30, and $40 \mathrm{rpm}$, respectively. The gate valve (labeled 6 in Figure 1) will be open when the temperature of liquid PEW at the bottom outlet of the cooling tank is not higher than $160^{\circ} \mathrm{C}$. Liquid PEW flows out, and then it is cooled to room temperature to prepare the PEW samples. 


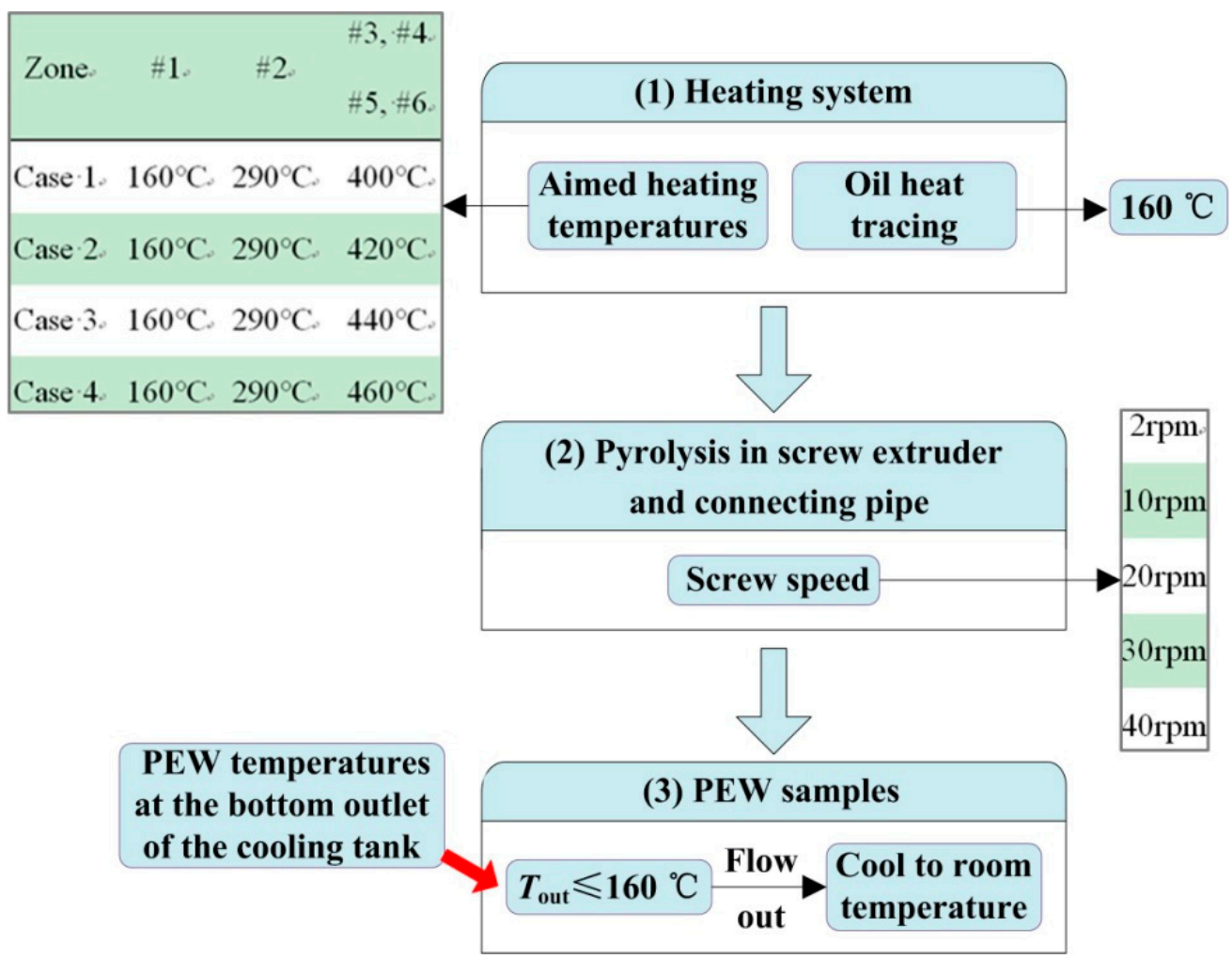

Figure 2. Flowchart of preparation of polyethylene wax (PEW).

Under different screw speeds, the flow time of material from the inlet of the SSE to the outlet of the connecting pipe was measured and the flow time of material from the inlet of the SSE to the inlet of Heating Zone \#3 was calculated. Then, the pyrolysis time of material was obtained by calculating the difference between the two flow times. Table 1 shows the correspondence between pyrolysis time and screw speeds.

Table 1. The correspondence between pyrolysis time and screw speeds.

\begin{tabular}{cccccc}
\hline Screw Speed (rpm) & 2 & 10 & 20 & 30 & 40 \\
\hline Pyrolysis Time (s) & 842 & 213 & 179 & 146 & 110 \\
\hline
\end{tabular}

\subsection{Characterization of Polyethylene Wax}

Liquid PEWs flow out when their temperatures are not higher than $160{ }^{\circ} \mathrm{C}$, the colors of which are shown in Figure 3 under different screw speeds at the pyrolysis temperature of $693 \mathrm{~K}$. With increasing the screw speed, it can be seen that the color of PEW lightens gradually. At a lower screw speed, more molecular chains of low molecular weight generate, and the PEW of lower molecular weight is more likely to be oxidized to yield a darker color.

DSC (Q600, Thermal Analysis Co., Newtown, PA, USA) and GPC (PL-GPC 220, Polymer Laboratories Co., Salop, UK) were used to measure the melting points, molecular weights, and molecular weight distributions of aforementioned PEWs. In addition, a universal calibration was used in this study. As shown in Figure 4, the effects of screw speed and pyrolysis temperature on the number-average molecular weight (NAMW) and melting point of PEW can be summarized as (1) the molecular weight and melting point of PEW increase with increasing the screw speed and decrease with increasing the pyrolysis temperature and (2) low screw speed and high pyrolysis temperature are expected to obtain the PEW of low molecular weight. 

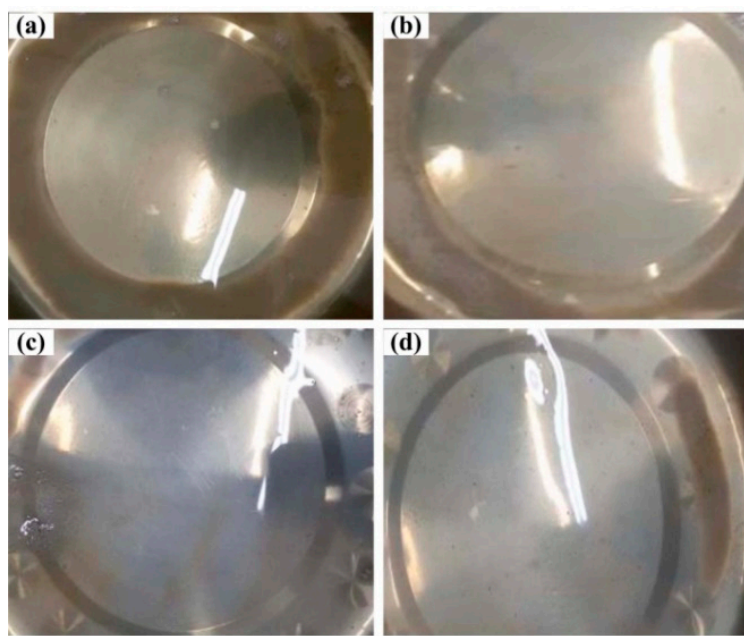

(d)

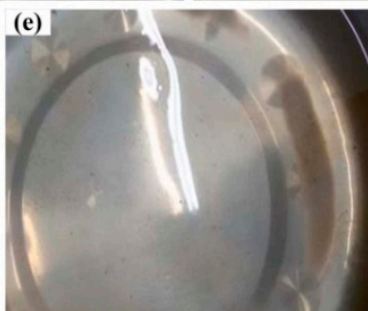

Figure 3. Liquid PEWs prepared under different screw speeds at the pyrolysis temperature of $693 \mathrm{~K}$. (a) $n=2 \mathrm{rpm},(\mathbf{b}) n=10 \mathrm{rpm},(\mathbf{c}) n=20 \mathrm{rpm},(\mathbf{d}) n=30 \mathrm{rpm},(\mathbf{e}) n=40 \mathrm{rpm}$.

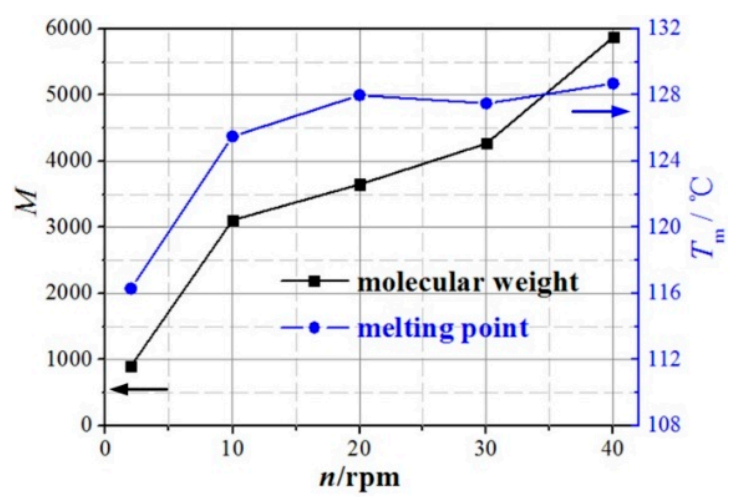

(a) $T_{\mathrm{p}}=693 \mathrm{~K}$

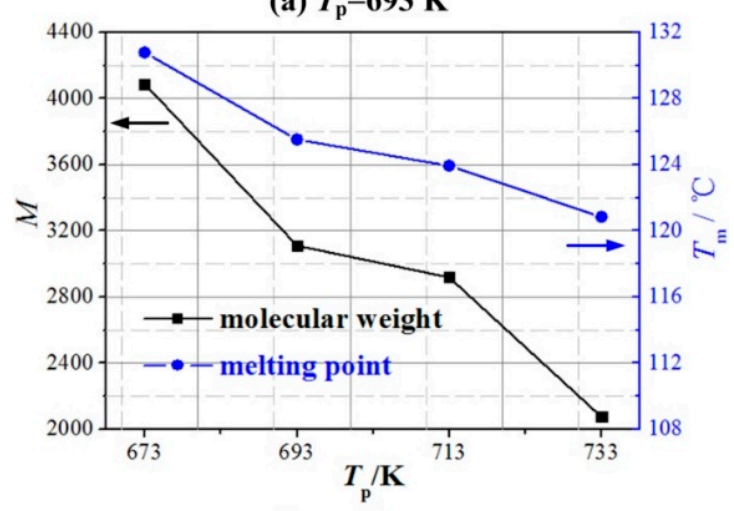

(b) $n=10 \mathrm{rpm}$

Figure 4. Effects of screw speed and pyrolysis temperature on the number-average molecular weight (NAMW) and melting point of PEW. (a) screw speed, (b) pyrolysis temperature. 
However, a too low screw speed or too high pyrolysis temperature is not suggested not only because of low efficiency or high energy consumption but also because of a too wide melting peak and many PEWs of low molecular weights as shown in red boxes in Figure 5. In engineering practice, a too wide melting peak and many PEWs of low molecular weights can result in poor thermal properties. It can be seen from Figure $5 \mathrm{a}-\mathrm{c}$, that for a fixed pyrolysis temperature, a wide melting peak (even double melting peaks) and many PEWs of low molecular weights occur when the screw speed reduces to $2 \mathrm{rpm}$, i.e., the screw speed of $2 \mathrm{rpm}$ is not desired. Likewise, for a fixed screw speed in Figure $5 \mathrm{~d}-\mathrm{f}$, the wide melting peak (even double melting peaks) and many PEWs of low molecular weights in Figure $5 \mathrm{f}$ indicate that the pyrolysis temperature of $733 \mathrm{~K}$ is not desired.

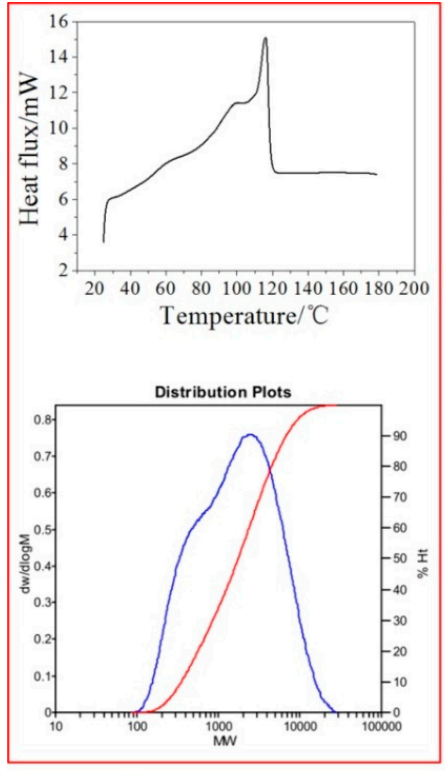

(a) $T_{\mathrm{p}}=693 \mathrm{~K}, n=2 \mathrm{rpm}$

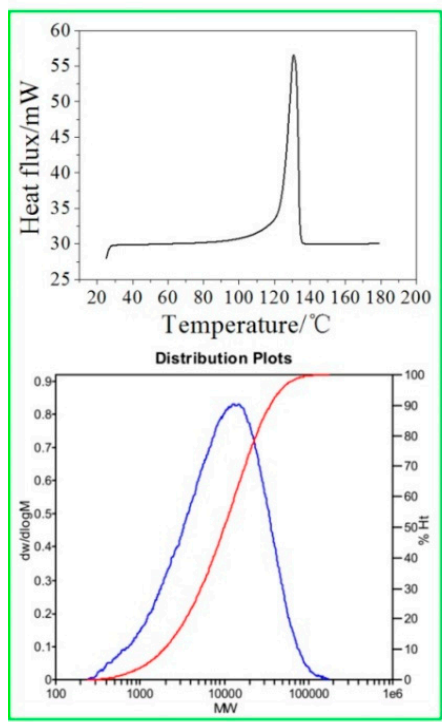

(d) $T_{\mathrm{p}}=673 \mathrm{~K}, n=10 \mathrm{rpm}$

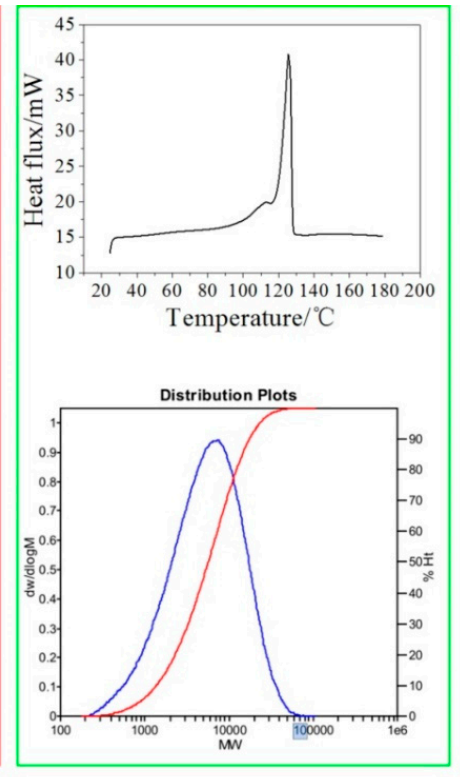

(b) $T_{\mathrm{p}}=693 \mathrm{~K}, n=10 \mathrm{rpm}$

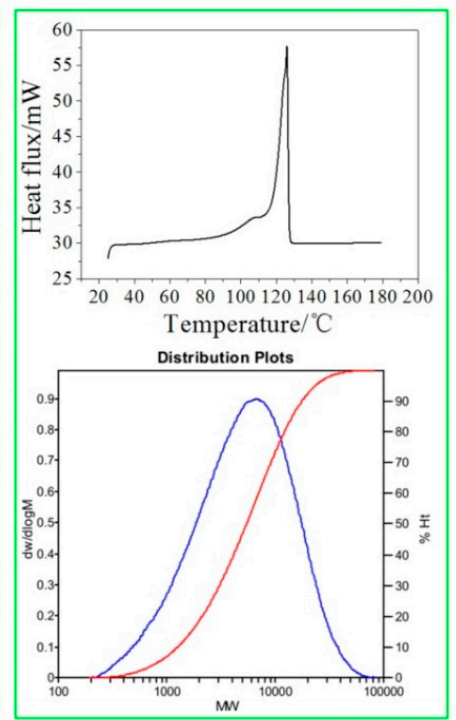

(e) $T_{\mathrm{p}}=713 \mathrm{~K}, n=10 \mathrm{rpm}$

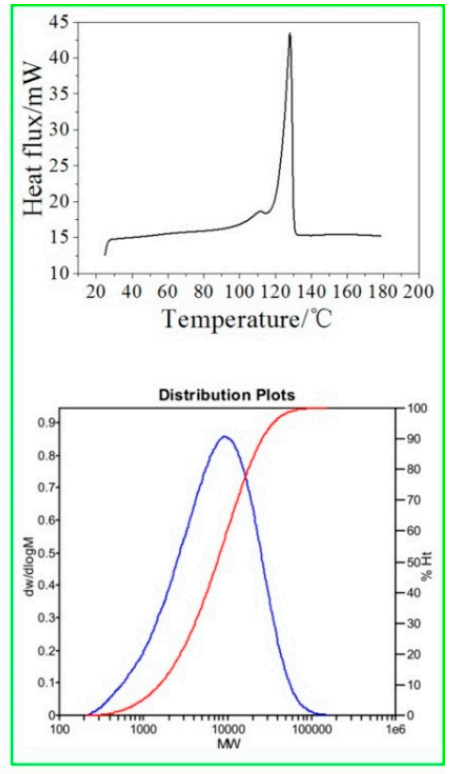

(c) $T_{\mathrm{p}}=693 \mathrm{~K}, n=20 \mathrm{rpm}$

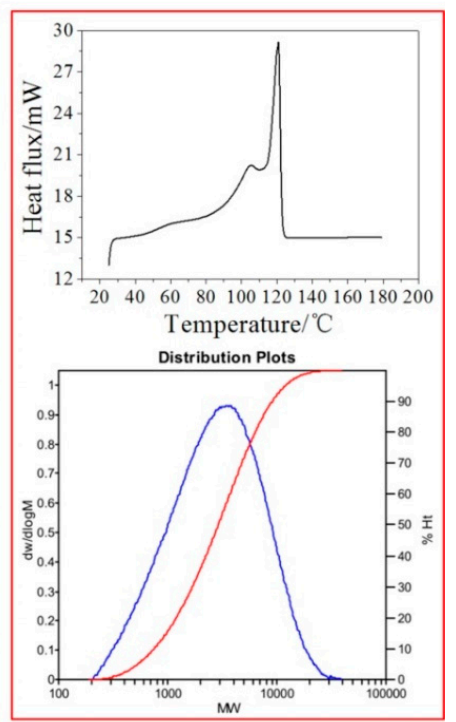

(f) $T_{\mathrm{p}}=733 \mathrm{~K}, n=10 \mathrm{rpm}$

Figure 5. Differential scanning calorimetry (DSC) curves and molecular weight distribution plots of PEWs under different screw speeds and pyrolysis temperatures. (a) $T_{\mathrm{p}}=693 \mathrm{~K}, n=2 \mathrm{rpm},(\mathbf{b}) T_{\mathrm{p}}=693$ $\mathrm{K}, n=10 \mathrm{rpm},(\mathbf{c}) T_{\mathrm{p}}=693 \mathrm{~K}, n=20 \mathrm{rpm},(\mathbf{d}) T_{\mathrm{p}}=673 \mathrm{~K}, n=10 \mathrm{rpm},(\mathbf{e}) T_{\mathrm{p}}=713 \mathrm{~K}, n=10 \mathrm{rpm},(\mathbf{f}) T_{\mathrm{p}}$ $=733 \mathrm{~K}, n=10 \mathrm{rpm}$. 
To sum up, both the screw speed and the pyrolysis temperature have an important effect on the NAMW of PEW. PEW of a desired NAMW and a narrow melting peak can be prepared from the pyrolysis of waste HDPE under appropriate screw speed and pyrolysis temperature. It can be helpful to develop the method of precisely monitoring NAMW of PEW from the available observations of pyrolysis temperature and screw speed.

\section{Theoretical Analysis of Pyrolysis Procedure}

\subsection{Pyrolysis Model}

Figure 6 shows the pyrolysis scheme of random scission for HDPE. To simplify our model, it is assumed that: (1) the pyrolysis occurs at any node of the molecular chain with an equal probability because of the quasi-linear molecular structure of HDPE; (2) based on the principle of random process, the pyrolysis can be expressed with the same reaction dynamic equation using the same reaction order; (3) the pyrolysis time does not vary with the changes in viscosity stemming from the different pyrolysis temperatures and only depends on the screw speed; and (4) the reaction rate constant is uniform in the whole heating zones \#3 to \#6 of the SSE and the connecting pipe.

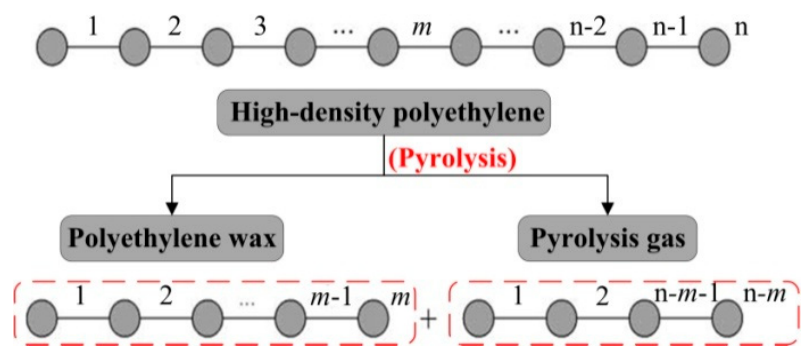

Figure 6. Pyrolysis scheme of random scission for high-density polyethylene (HDPE).

\subsection{Theoretical Calculation of Average Carbon-Atom Number of PEW}

The governing equation for the pyrolysis of HDPE is:

$$
\frac{d r}{d t}=(1-r)^{v} \cdot k\left(T_{p}\right)
$$

It is assumed that the total number of molecular chain nodes that are not pyrolyzed is $b$. At time $t$ $=0 \mathrm{~s}$, there are no pyrolyzed nodes, and the pyrolysis ratio $r=0$. Therefore, the pyrolysis ratio $r$ can be defined by:

$$
r=1-\frac{b(r)}{b(0)}
$$

where $b(0)$ and $b(r)$ represent the numbers of not pyrolyzed nodes at pyrolysis ratio of 0 and $r$. The pyrolysis ratio of HDPE is $r$ at time $t$. At pyrolysis ratio $r$, it is assumed that the total number of molecule chains with $m$ carbon atoms is $N_{m}$. Therefore, we obtain the following equation:

$$
b(r)=\sum_{m=1}^{\mathrm{n}}\left((m-1) \cdot N_{m}(r)\right)
$$

When the pyrolysis ratio increases from $r$ to $r+\Delta r$, the increased number of molecule chains with $m$ carbon atoms is:

$$
\Delta N_{m}^{+}=b(0) \cdot \Delta r \cdot \sum_{i=m+1}^{\mathrm{n}}\left(N_{i}(r) \cdot \frac{i-1}{b(r)} \cdot \frac{2}{i-1}\right)=\frac{2 \Delta r}{1-r} \sum_{i=m+1}^{\mathrm{n}} N_{i}(r)
$$


and the decreased number of molecule chains with $m$ carbon atoms is:

$$
\Delta N_{m}^{-}=b(0) \cdot \Delta r \cdot \frac{(m-1) N_{m}(r)}{b(r)}=(m-1) N_{m}(r) \frac{\Delta r}{1-r}
$$

Therefore, at pyrolysis ratio $r+\Delta r$, the total number of molecule chains with $m$ carbon atoms is:

$$
N_{m}(r+\Delta r)=N_{m}(r)+\frac{2 \Delta r}{1-r} \sum_{i=m+1}^{\mathrm{n}} N_{i}(r)-(m-1) N_{m}(r) \frac{\Delta r}{1-r}
$$

and Equation (6) can be rewritten as an ordinary differential Equation:

$$
\frac{d N_{m}(r)}{d r}=\frac{2}{1-r} \sum_{i=m+1}^{\mathrm{n}} N_{i}(r)-\frac{(m-1) N_{m}(r)}{1-r}
$$

By solving Equation (7), the following equation is obtained:

$$
N_{m}(r)=C \cdot r^{2} \cdot(1-r)^{m-1}
$$

where $C$ is a constant number.

In this study, the evaporation temperature equals the temperature of the oil heat tracing, i.e., $433 \mathrm{~K}$. According to Wallis and Bhatia [33], the relationship between the maximum carbon-atom number of pyrolysis gas $m_{v}$ and the evaporation temperature $T_{\mathrm{V}}$ is:

$$
m_{v}=9 \times 10^{-5} T_{\mathrm{v}}{ }^{2}-0.0317 T_{\mathrm{v}}+5.1497
$$

At pyrolysis ratio $r$, the average carbon-atom number of PEW $\bar{M}(r)$ can be given by:

$$
\bar{M}(r)=\frac{\sum_{m=m_{v}}^{\mathrm{n}} m N_{m}(r)}{\sum_{m=m_{v}}^{\mathrm{n}} N_{m}(r)}=\frac{\sum_{m=m_{v}}^{\mathrm{n}} m(1-r)^{m-1}}{\sum_{m=m_{v}}^{\mathrm{n}}(1-r)^{m-1}}
$$

where $\sum_{m=m_{v}}^{\mathrm{n}} m(1-r)^{m-1}$ and $\sum_{m=m_{v}}^{\mathrm{n}}(1-r)^{m-1}$ can be obtained by Equations (11) and (12):

$$
\begin{aligned}
& \sum_{m=m_{v}}^{\mathrm{n}} m(1-r)^{m-1}=(1-r)^{m_{v}-1}\left\{m_{v} \sum_{j=1}^{\mathrm{n}-m_{v}+1}(1-r)^{j-1}+(1-r) \sum_{j=1}^{\mathrm{n}-m_{v}} j(1-r)^{j-1}\right\} \\
& \approx(1-r)^{m_{v}-1}\left(\frac{m_{v}}{r}+\frac{1-r}{r^{2}}\right)(\mathrm{n} \rightarrow+\infty) \\
& \sum_{m=m_{v}}^{\mathrm{n}}(1-r)^{m-1}=\frac{(1-r)^{m_{v}-1}}{r}\left[1-(1-r)^{\mathrm{n}-m_{v}+1}\right] \approx \frac{(1-r)^{m_{v}-1}}{r}(\mathrm{n} \rightarrow+\infty)
\end{aligned}
$$

Therefore, Equation (10) can be rewritten as:

$$
\bar{M}(r) \approx m_{v}+\frac{1}{r}-1
$$

\section{Monitoring Procedure for Average Molecular Weight of Polyethylene Wax}

The procedure to precisely monitor NAMW of PEW from the pyrolysis of waste HDPE by extrusion is summarized as follows and shown in Figure 7: 


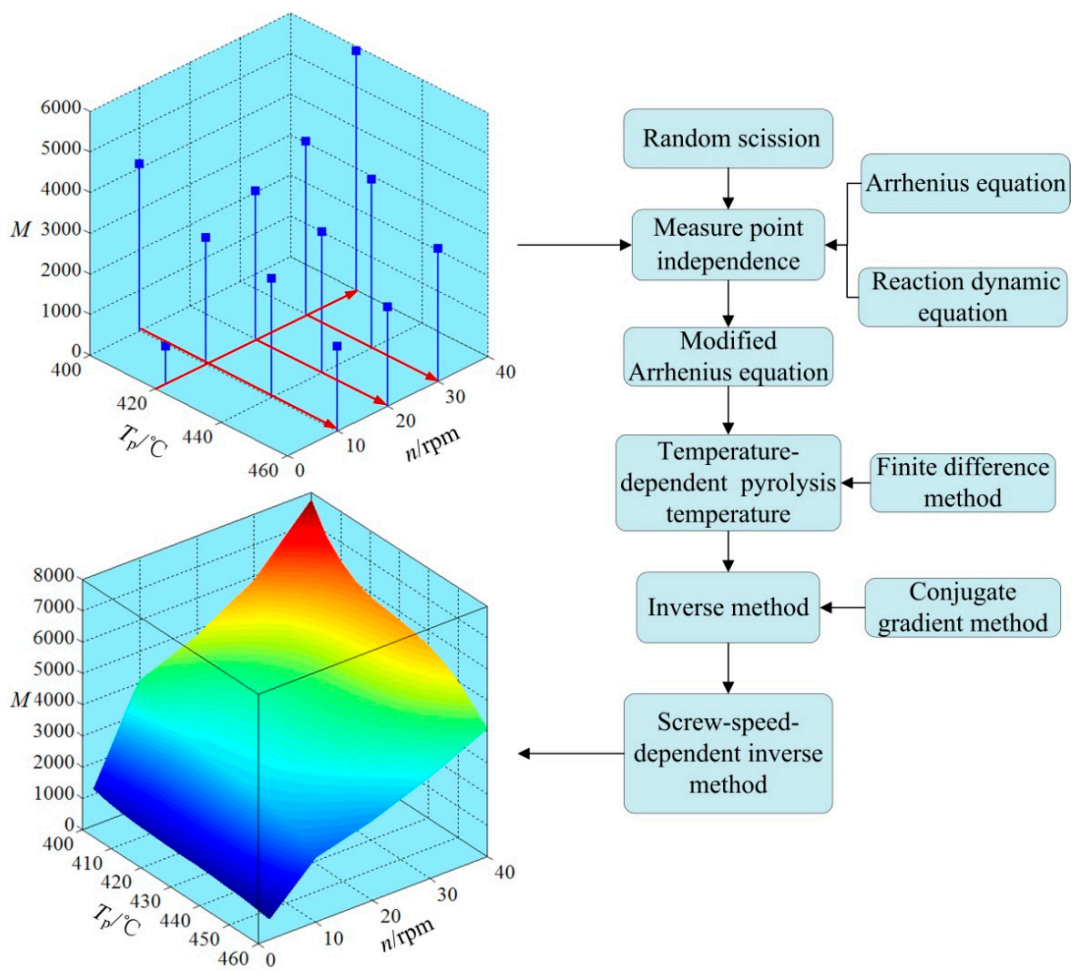

Figure 7. Procedure to monitor NAMW of PEW from the pyrolysis of waste HDPE by extrusion.

Step 1. Measure point independence verification is conducted based on the pyrolysis mechanism of random scission, Arrhenius equation, and the reaction dynamic equation by using experimental data at measure points N1, N2, N3, N6, N8, N9, N10, and N12 (refer to Table 2).

Table 2. The arrangements of measure points under different values of $p$.

\begin{tabular}{|c|c|c|c|c|c|c|c|c|c|c|c|c|}
\hline Pyrolysis Temperature (K) & 673 & & & 693 & & & & 713 & & & 733 & \\
\hline Screw Speed (rpm) & 10 & 2 & 10 & 20 & 30 & 40 & 10 & 20 & 30 & 10 & 20 & 30 \\
\hline NAMW of PEW & 4088 & 908 & 3111 & 3649 & 4268 & 5876 & 2919 & 3458 & 4151 & 2075 & 2445 & 3274 \\
\hline $\begin{array}{c}\text { Measure point } \\
p=4\end{array}$ & $\begin{array}{c}\mathrm{N} 1 \\
\sqrt{ }\end{array}$ & $\begin{array}{c}\mathrm{N} 2 \\
\sqrt{ }\end{array}$ & N3 & $\mathrm{N} 4$ & N5 & $\begin{array}{c}\mathrm{N} 6 \\
\sqrt{ }\end{array}$ & N7 & N8 & N9 & $\begin{array}{c}\mathrm{N} 10 \\
\sqrt{ }\end{array}$ & N11 & N12 \\
\hline$p=6$ & $\sqrt{ }$ & $\sqrt{ }$ & & & & $\sqrt{ }$ & & $\sqrt{ }$ & $\sqrt{ }$ & $\sqrt{ }$ & & \\
\hline$p=8$ & $\sqrt{ }$ & $\sqrt{ }$ & $\sqrt{ }$ & & & $\sqrt{ }$ & & $\sqrt{ }$ & $\sqrt{ }$ & $\sqrt{ }$ & & $\sqrt{ }$ \\
\hline
\end{tabular}

Step 2. The modified Arrhenius equation is used to fit the relationship between the reaction rate constant $k\left(T_{\mathrm{p}}\right)$ and the pyrolysis temperature $T_{\mathrm{p}}$.

Step 3. The effect of the inevitable small fluctuations of pyrolysis temperature stemming from a temperature control system on monitoring precision is studied.

Step 4. With the results of the modified Arrhenius equation $(o=3)$ used as initial values, an inverse estimation based on the conjugate gradient method is introduced for higher precision.

Step 5. A screw-speed-dependent inverse method is proposed to further improve the monitoring precision of NAMW of PEW for $\Omega=[2,40] \times[400,460]$.

\subsection{Arrhenius Equation}

According to Westerhout R W J [34], a first-order reaction dynamic equation can be used because the conversion ratio of the feedstock (waste HDPE) is higher than $98 \%$ during our tests. Therefore, in this study, Equation (1) can be rewritten as:

$$
\frac{d r}{d t}=(1-r) \cdot k\left(T_{\mathrm{p}}\right)
$$


The initial condition is:

$$
r(0)=0
$$

By solving Equations (14) and (15), we obtain:

$$
r=1-e^{-k\left(T_{\mathrm{p}}\right) \cdot t}
$$

The pyrolysis time $t$ in Equation (16) can be obtained from the screw speed $n$ (refer to Table 1), while the pyrolysis ratio $r$ in Equation (16) can be obtained from the evaporation temperature $T_{\mathrm{v}}$ and the average carbon-atom number of PEW $\bar{M}(r)$ using Equations (9) and (13). Thus, the reaction rate constant $k\left(T_{\mathrm{p}}\right)$ can be easily obtained. After taking logarithm of Arrhenius equation, we obtain:

$$
\ln k\left(T_{\mathrm{p}}\right)=\ln A_{1}-\frac{E}{R T_{\mathrm{p}}}
$$

Based on a linear regression, the factor before exponent $A_{1}$ and the activation energy $E$ can be determined using our partial test data.

\subsection{Measure-Point-Independence Verification}

Table 2 shows the arrangements of measure points under different values of $p$, where $p$ represents the number of measure points. It is worth mentioning that a measure point here represents one group of test: pyrolysis temperature, screw speed, and corresponding NAMW of PEW; therefore, there are twelve measure points for our tests in total.

To get a measure-point-independent solution, we added measure-point-independence verification into our program. Figure 8a shows a flowchart of the measure-point-independence verification. During the measure-point-independence verification, based on a linear regression, we solved the Arrhenius equation for the pyrolysis of HDPE under a series of measure point arrangements. Figure $8 \mathrm{~b}$ shows the Arrhenius equations obtained under different measure point arrangements. It can be seen that the results at $p=4,6$, and 8 show the same trend. Careful comparisons of the results indicate that the average relative difference is smaller than $4.38 \%$ between $p=4$ and $p=6$ and smaller than $0.82 \%$ between $p=6$ and $p=8$.

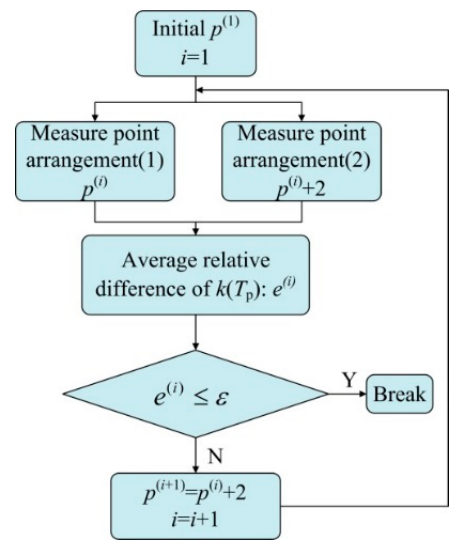

(a)

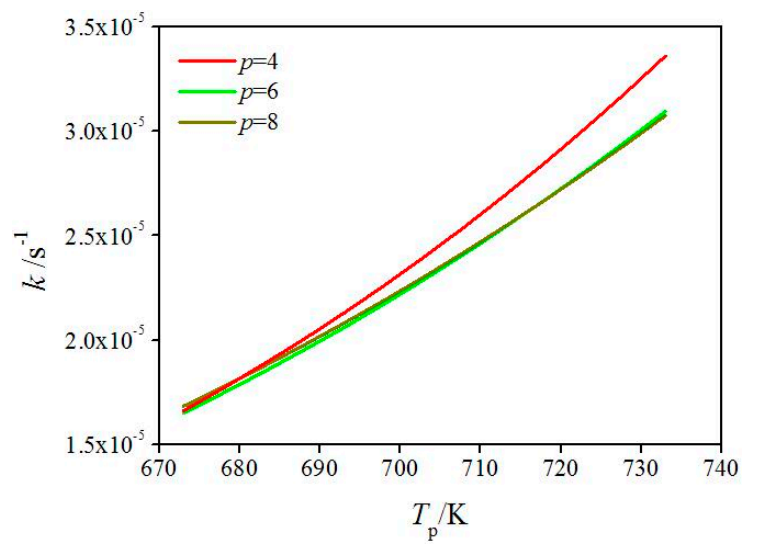

(b)

Figure 8. Measure-point-independence verification. (a) flowchart of measure-point-independence verification, (b) comparisons of Arrhenius equations obtained at four, six, and eight measure points.

\subsection{Modified Arrhenius Equation}

During the monitoring procedure, the measured NAMWs of PEWs at measure points N1, N2, N3, N6, N8, N9, N10, and N12 (refer to Table 2) were used as input data. To validate the monitoring results, 
we compared the measured and calculated NAMWs of PEWs at measure points N4, N5, N7, and N11 (refer to Table 2). As shown in Figure 9, the reaction rate constants for $o=1,2$, and 3 show the same trend; however, the curves for $o=1$ and 2 are similar, while the curve for $o=3$ is obviously different from them. The curve for $o=3$ is smoother than those for $o=1$ and 2 for the reason that the modified Arrhenius equation with a higher-order allows more degrees of freedom. Thus, the curve for $o=3$ is expected to be more approaching to the real relationship between reaction rate constant and pyrolysis temperature than those for $o=1$ and 2. The relative errors of NAMW of PEW at four measure points (N4, N5, N7, and N11) for initial and modified Arrhenius equations are shown in Table 3. It can be seen that the mean relative error of NAMW of PEW at aforementioned measure points reduces to $3.6 \%$ from $8.1 \%$.

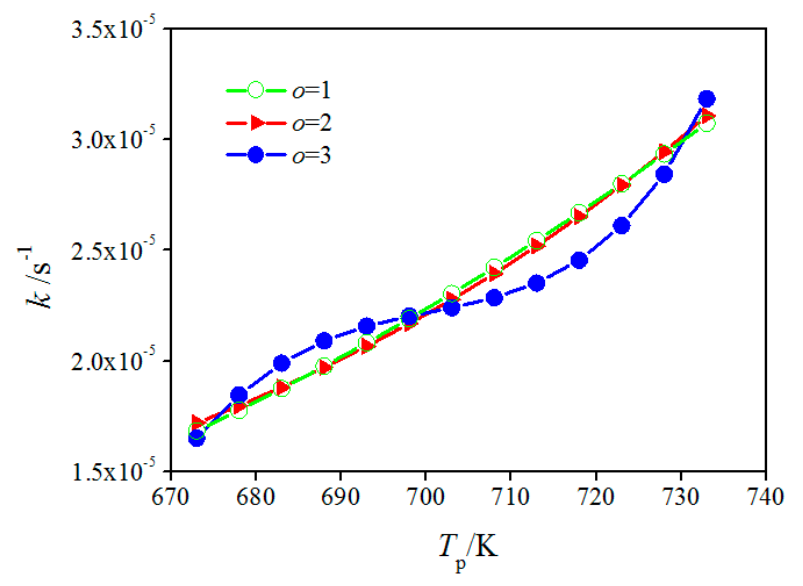

Figure 9. Comparisons of initial and modified Arrhenius equations.

Table 3. Relative errors of NAMW of PEW at four measure points (N4, N5, N7, and N11) for initial and modified Arrhenius equations.

\begin{tabular}{ccccccc}
\hline Equation Order & Initial or Modified Arrhenius Equation & $\mathbf{N 4}(\mathbf{\%})$ & $\mathbf{N 5}(\%)$ & $\mathbf{N 7}(\%)$ & N11 (\%) & Mean (\%) \\
\hline$o=1$ & $\ln k\left(T_{\mathrm{p}}\right)=-3.6-4948.9 / T_{\mathrm{p}}$ & 5.8 & 10.4 & 8.0 & 8.3 & 8.1 \\
$\ln k\left(T_{\mathrm{p}}\right)=$ & 6.6 & 11.3 & 7.1 & 7.2 & 8.0 \\
$o=2$ & $\begin{array}{c}11.6-2.6 \times 10^{4} / T_{\mathrm{p}}+7.6 \times 10^{6} / T_{\mathrm{p}}{ }^{2} \\
\ln k\left(T_{\mathrm{p}}\right)=2.9 \times 10^{3}-6.2 \times 10^{6} / T_{\mathrm{p}}+4.3 \times \\
10^{9} / T_{\mathrm{p}}{ }^{2}-1.0 \times 10^{12} / T_{\mathrm{p}}{ }^{3}\end{array}$ & 2.2 & 6.7 & 0.8 & 4.7 & 3.6 \\
\hline
\end{tabular}

\subsection{Time-Dependent Pyrolysis Temperature}

During our tests, the small fluctuations of pyrolysis temperature stemming from the temperature control system were inevitable. To study the effect of the time-dependent pyrolysis temperature on monitoring precision, the fluctuations of pyrolysis temperature were assumed as the following Equation:

$$
\Delta T_{\mathrm{p}}=A_{2} \sin (2 \pi / l \cdot t)
$$

When the pyrolysis temperature varied as time, the reaction rate constant $k\left(T_{\mathrm{p}}\right)$ in Equation (14) should not be regarded as a time-independent constant, i.e., Equation (16) was no longer valid. In this situation, an analytical solution was no longer easy; therefore, we solved the Equation (14) by the finite difference method. The NAMWs of PEWs were estimated at $l=60 \mathrm{~s}$ under different amplitudes of temperature fluctuation as shown in Figure 10. It can be seen that the relative errors of NAMW of PEW are similar when the amplitude of temperature fluctuation is not larger than $1 \mathrm{~K}$, an indication that the time-dependent pyrolysis temperature will not improve the precision much but increase the computational cost. Larger fluctuations were not considered for the reason that the controlment precision of the pyrolysis temperature was within $1 \mathrm{~K}$. 


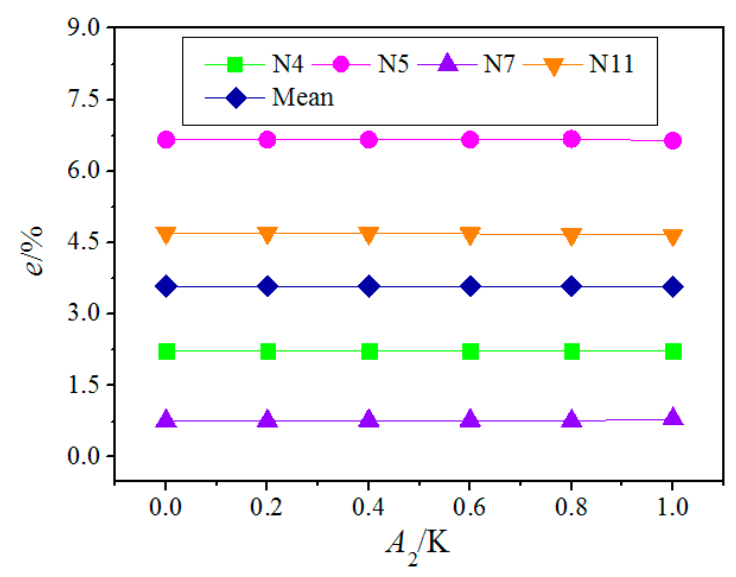

Figure 10. Effect of fluctuation amplitude of pyrolysis temperature on monitoring precision. $A_{2}$ : (the fluctuation amplitude of pyrolysis temperature); $e$ : (the relative errors of NAMW of PEW).

\subsection{Inverse Method}

During an inverse estimation, the reaction rate constant $k\left(T_{\mathrm{p}}\right)$ is assumed, and the corresponding NAMWs of PEWs are calculated. The calculated NAMWs of PEWs are compared with the measured values. Because the inverse estimation can be treated as an optimization problem, we use an objective function based on the least-squares method for the inverse estimation:

$$
J=\sum_{i=1}^{Z}\left[M_{i, \text { cal }}-M_{i, \text { mea }}\right]^{2}
$$

$J$ is a function of $M_{i, \text { cal }}$, and $M_{i, \text { cal }}$ varies with $k\left(T_{\mathrm{p}}\right)$. Therefore, $J$ is a function of $k\left(T_{\mathrm{p}}\right)$, and we obtain the optimization problem:

$$
\min J=J\left[k\left(T_{\mathrm{p}}\right)\right]
$$

The optimization problem can be solved by the following iterative format:

$$
k\left(T_{\mathrm{p}}\right)^{(j+1)}=k\left(T_{\mathrm{p}}\right)^{(j)}+\beta^{(j)} d^{(j)}
$$

When we use the conjugate gradient method, $d^{(j)}$ is given by the following equation:

$$
d^{(j)}=-\nabla J\left(k\left(T_{\mathrm{p}}\right)^{(j)}\right)+\frac{\left\|\nabla J\left(k\left(T_{\mathrm{p}}\right)^{(j)}\right)\right\|^{2}}{\left\|\nabla J\left(k\left(T_{\mathrm{p}}\right)^{(j-1)}\right)\right\|^{2}} d^{(j-1)}
$$

and $\beta^{(j)}$ should meet the following condition:

$$
J\left(k\left(T_{\mathrm{p}}\right)^{(j)}+\beta^{(j)} d^{(j)}\right)=\min _{\beta \geq 0} J\left(k\left(T_{\mathrm{p}}\right)^{(j)}+\beta d^{(j)}\right)
$$

It is clear that $k\left(T_{\mathrm{p}}\right)^{(1)}$ is not the true value; however, with the iteration process, $k\left(T_{\mathrm{p}}\right)^{(j)}$ can approach the true value when the stopping criterion is met:

$$
\left\|d^{(j)}\right\| \leq \varepsilon
$$

For the aforementioned inverse estimation, the reaction rate constant $k\left(T_{\mathrm{p}}\right)$ is only a function of the pyrolysis temperature $T_{\mathrm{p}}$. However, the pyrolysis reaction is under both external heater and internal shear heat, and the screw speed should have an effect on the reaction rate constant; i.e., it is 
more reasonable that the reaction rate constant $k\left(T_{\mathrm{p}}, n\right)$ is a function of the pyrolysis temperature $T_{\mathrm{p}}$ and the screw speed $n$. Therefore, $k\left(T_{\mathrm{p}}\right)$ in Equations (18)-(23) should be replaced with $k\left(T_{\mathrm{p}}, n\right)$.

Reaction rate constants for the modified Arrhenius equation $(o=3)$, inverse method, and screw-speed-dependent inverse method are compared in Figure 11. It can be seen that the reaction rate constants for the aforementioned three methods show the same trend with increasing the pyrolysis temperature; however, small differences in values of the reaction rate constants can be found. In order to carefully check these differences, the relative errors of NAMW of PEW at four measure points (N4, N5, N7, and N11) for the inverse method and screw-speed-dependent inverse method are shown in Table 4. Compared with the initial and modified Arrhenius equations in Table 3, both the inverse method and the screw-speed-dependent inverse method are of higher precision. It is meaningful that the monitoring precision is improved by $69.1 \%$ from the initial Arrhenius equation to the screw-speed-dependent inverse method.

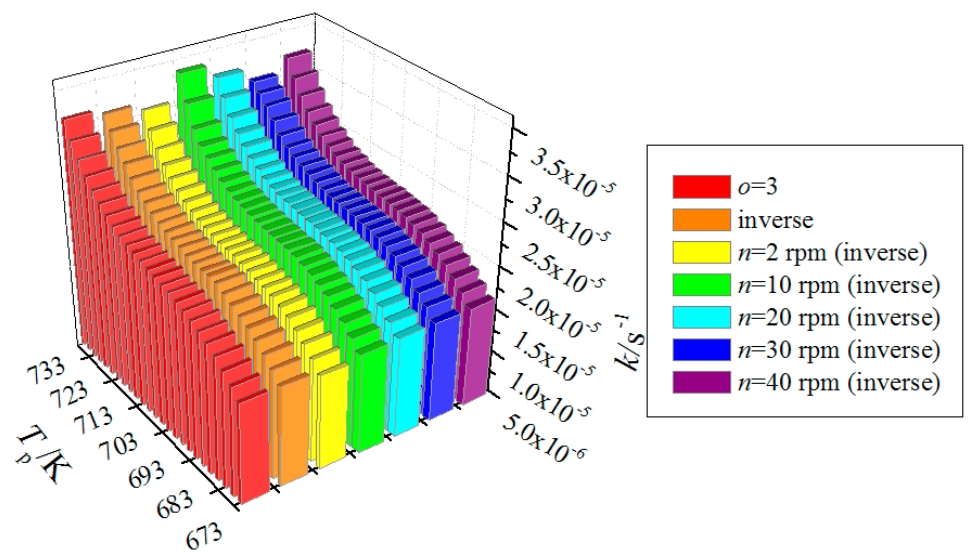

Figure 11. Comparisions of reaction rate constants between the modified Arrhenius equation $(o=3)$, inverse method, and screw-speed-dependent inverse method.

Table 4. Relative errors of NAMW of PEW at four measure points (N4, N5, N7, and N11) for the modified Arrhenius equation $(o=3)$, inverse method, and screw-speed-dependent inverse method.

\begin{tabular}{cccccc}
\hline Relative Error (\%) & N4 & N5 & N7 & N11 & Mean \\
\hline modified Arrhenius equation $(o=3)$ & 2.2 & 6.7 & 0.8 & 4.7 & 3.6 \\
Inverse method & 0.2 & 4.6 & 0.9 & 6.7 & 3.1 \\
Screw-speed-dependent inverse method & 0.6 & 4.8 & 0.2 & 4.5 & 2.5 \\
\hline
\end{tabular}

\section{Conclusions}

Using a test platform, PEW was prepared from the pyrolysis of waste HDPE in a SSE and a connecting pipe. A program was developed in MATLAB to monitor NAMW of PEW from pyrolysis temperature and screw speed. The measured NAMWs of PEWs at measure points N4, N5, N7, and N11, which were not used as input data for the monitoring program, were compared with the calculated values to validate the monitoring. Our results showed that: (1) PEW of the controlled NAMW with a narrow melting peak was able to be prepared continuously from the pyrolysis of waste HDPE by extrusion; (2) the mathematical model by measure-point-independence verification showed good agreement with experimental results, and the average relative error of NAMW of PEW was not larger than $8.1 \%$ for the initial Arrhenius equation; (3) with the modified Arrhenius equation $(o=3)$, the average relative errors of NAMW of PEW for time-independent and time-dependent pyrolysis temperatures were similar and not larger than $3.59 \%$ and $3.58 \%$, respectively; and (4) the average relative errors of NAMW of PEW for the inverse method and screw-speed-dependent inverse method were not larger than $3.1 \%$ and $2.5 \%$, respectively, an indication that the monitoring program was able to precisely monitor NAMW of PEW from the pyrolysis of waste HDPE by extrusion. 
Author Contributions: Conceptualization: P.X. Funding acquisition: P.X.; Investigation: Z.G. and X.L.; Methodology: Z.G. and X.L.; Resources: P.X.; Software: Z.G.; Validation: X.L.; Writing-original draft: Z.G.; Writing-review \& editing: P.X. All authors have read and agreed to the published version of the manuscript.

Funding: This research and the APC were funded by the National Natural Science Foundation of China (grant number 51673021).

Acknowledgments: This work was supported by the National Natural Science Foundation of China (Project No. 51673021).

Conflicts of Interest: The authors declare no conflict of interest.

\section{Nomenclature}

$A_{1}: \quad$ the factor before exponent, $\mathrm{s}^{-1}$

$A_{2}$ : the amplitude of temperature fluctuation, $\mathrm{K}$

$b$ : the number of not pyrolyzed nodes

$d$ : search direction

E: activation energy, $\mathrm{kJ} / \mathrm{mol}$

$J: \quad$ objective function

$k$ : reaction rate constant

$l$ : the period of temperature fluctuation, $\mathrm{s}$

$m$ : carbon-atom number

$M$. the number-average molecular weight of

M: $\quad$ polyethylene wax

$\bar{M}$ : the average carbon-atom number of moleculars of polyethylene wax

$n: \quad$ screw speed

$\mathrm{n}$. the maximum carbon-atom number of moleculars of

polyethylene wax

$N_{m}$ : the number of moleculars of polyethylene wax with

$m$ carbon atoms
$\mathrm{N}$ measure point (a test under a specific process

$\mathrm{N}$ : condition)

o: the equation order of initial or modified Arrhenius

o: equation

$p: \quad$ measure point number

$r$ : $\quad$ pyrolysis ratio

$R: \quad$ gas constant $(8.314 \mathrm{~J} /(\mathrm{mol} \cdot \mathrm{K}))$

$T: \quad$ temperature, $\mathrm{K}$

$t$ : time

$v: \quad$ the order of reaction dynamic equation

$Z$ : $\quad$ the total number of input measure points

\section{Greek Symbols}

$\beta$ : $\quad$ search step size

$\Delta r: \quad$ the increment of pyrolysis ratio

$\Delta T: \quad$ temperature fluctuation, $\mathrm{K}$

$\varepsilon: \quad$ a small positive number

$\Omega$ : computational domain

\section{Subscripts}

cal: calculated

m: melting point

mea: measured

p: pyrolysis

v: evaporation

Superscripts

$i, j: \quad$ iteration index 


\section{References}

1. Verespej, M. HDPE recycling remains stagnant at 29.9\%. Waste Recycl. News 2013, 18, 19.

2. Okan, M.; Aydin, H.M.; Barsbay, M. Current approaches to waste polymer utilization and minimization: A review. J. Chem. Technol. Biotechnol. 2019, 94, 8-21. [CrossRef]

3. Ragaert, K.; Delva, L.; Van Geem, K. Mechanical and chemical recycling of solid plastic waste. Waste Manag. 2017, 69, 24-58. [CrossRef]

4. Rodríguez, E.; Gutiérrez, A.; Palos, R.; Vela, F.J.; Arandes, J.M.; Bilbao, J. Fuel production by cracking of polyolefins pyrolysis waxes under fluid catalytic cracking (FCC) operating conditions. Waste Manag. 2019, 93, 162-172. [CrossRef]

5. Al-Salem, S.M.; Antelava, A.; Constantinou, A.; Manos, G.; Dutta, A. A review on thermal and catalytic pyrolysis of plastic solid waste (PSW). J. Environ. Manag. 2017, 197, 177-198. [CrossRef]

6. Wong, S.L.; Ngadi, N.; Abdullah, T.A.T.; Inuwa, I.M. Current state and future prospects of plastic waste as source of fuel: A review. Renew. Sustain. Energy Rev. 2015, 50, 1167-1180. [CrossRef]

7. Lopez, G.; Artetxe, M.; Amutio, M.; Alvarez, J.; Bilbao, J.; Olazar, M. Recent advances in the gasification of waste plastics. A critical overview. Renew. Sustain. Energy Rev. 2018, 82, 576-596. [CrossRef]

8. Arena, U. Process and technological aspects of municipal solid waste gasification. A review. Waste Manag. 2012, 32, 625-639. [CrossRef] [PubMed]

9. Fox, J.A.; Stacey, N.T. Process targeting: An energy based comparison of waste plastic processing technologies. Energy 2019, 170, 273-283. [CrossRef]

10. Lopez, G.; Artetxe, M.; Amutio, M.; Bilbao, J.; Olazar, M. Thermochemical routes for the valorization of waste polyolefinic plastics to produce fuels and chemicals. A review. Renew. Sustain. Energy Rev. 2017, 73, 346-368. [CrossRef]

11. Akubo, K.; Nahil, M.A.; Williams, P.T. Aromatic fuel oils produced from the pyrolysis-catalysis of polyethylene plastic with metal-impregnated zeolite catalysts. J. Energy Inst. 2019, 92, 195-202. [CrossRef]

12. Ben, H.; Wu, Z.; Han, G.; Jiang, W.; Ragauskas, A. Pyrolytic Behavior of Major Biomass Components in Waste Biomass. Polymers 2019, 11, 324. [CrossRef] [PubMed]

13. Jiang, L.; Wu, N.; Zheng, A.; Wang, X.; Feng, X. Effect of Glycerol Pretreatment on Levoglucosan Production from Corncobs by Fast Pyrolysis. Polymers 2017, 9, 599. [CrossRef] [PubMed]

14. Wang, Y.; Huang, Y.; Dai, L.; Roger, R.; Wang, X. Preparation of fuel from co-pyrolysis of waste vegetable oil and waste polyethylene plastics. Trans. Chin. Soc. Agric. Mach. 2016, 47. [CrossRef]

15. Zhang, Y.; Duan, D.; Lei, H.; Villota, E.; Ruan, R. Jet fuel production from waste plastics via catalytic pyrolysis with activated carbons. Appl. Energy 2019, 251, 113337. [CrossRef]

16. Wallis, M.D.; Bhatia, S.K. Thermal degradation of high density polyethylene in a reactive extruder. Polym. Degrad. Stab. 2007, 92, 1721-1729. [CrossRef]

17. Scheirs, J.; Kaminsky, W.; Scheirs, J.; Kaminsky, W. Feedstock Recycling and Pyrolysis of Waste Plastics: Converting Waste Plastics into Diesel and other Fuels; John Wiley and Sons Ltd.: West Sussex, UK, 2006; p. 816.

18. Madorsky, S.L.; Straus, S.; Thompson, D.; Williamson, L. Pyrolysis of polyisobutene (vistanex), polyisoprene, polybutadiene, GR-S, and polyethylene in a high vacuum. J. Polym. Sci. 1949, 4, 639-664. [CrossRef]

19. Jellinek, H.H.G. Thermal degradation of polystyrene and polyethylene. Part III. J. Polym. Sci. 1949, 4, 13-36. [CrossRef]

20. Wall, L.A.; Madorsky, S.L.; Brown, D.W.; Straus, S.; Simha, R. The Depolymerization of Polymethylene and Polyethylene. J. Am. Chem. Soc. 1954, 76, 3430-3437. [CrossRef]

21. Poutsma, M.L. Reexamination of the Pyrolysis of Polyethylene: Data Needs, Free-Radical Mechanistic Considerations, and Thermochemical Kinetic Simulation of Initial Product-Forming Pathways. Macromolecules 2003, 36, 8931-8957. [CrossRef]

22. Tsuchiya, Y.; Sumi, K. Thermal decomposition products of polymethylene. J. Polym. Sci. Part B Polym. Lett. 1968, 6, 357-361. [CrossRef]

23. Tsuchiya, Y.; Sumi, K. Thermal decomposition products of polyethylene. J. Polym. Sci. Part A-1 Polym. Chem. 1968, 6, 415-424. [CrossRef]

24. Seeger, M.; Cantow, H.-J. Thermische spaltungsmechanismen in homo-und copolymeren aus $\alpha$-olefinen, 1. Grundlegende mechanismen und pyrolyse von linearem polyäthylen. Die Makromolekulare Chemie 1975, 176, 1411-1425. [CrossRef] 
25. Kiran, E.; Gillham, J.K. Pyrolysis-molecular weight chromatography: A new on-line system for analysis of polymers. II. Thermal decomposition of polyolefins: Polyethylene, polypropylene, polyisobutylene. J. Appl. Polym. Sci. 1976, 20, 2045-2068. [CrossRef]

26. Gascoin, N.; Navarro-Rodriguez, A.; Gillard, P.; Mangeot, A. Kinetic modelling of high density polyethylene pyrolysis: Part 1. Comparison of existing models. Polym. Degrad. Stab. 2012, 97, 1466-1474. [CrossRef]

27. Ranzi, E.; Dente, M.; Faravelli, T.; Bozzano, G.; Fabini, S.; Nava, R.; Cozzani, V.; Tognotti, L. Kinetic modeling of polyethylene and polypropylene thermal degradation. J. Anal. Appl. Pyrolysis 1997, 40,305-319. [CrossRef]

28. Faravelli, T.; Bozzano, G.; Scassa, C.; Perego, M.; Fabini, S.; Ranzi, E.; Dente, M. Gas product distribution from polyethylene pyrolysis. J. Anal. Appl. Pyrolysis 1999, 52, 87-103. [CrossRef]

29. Marongiu, A.; Faravelli, T.; Ranzi, E. Detailed kinetic modeling of the thermal degradation of vinyl polymers. J. Anal. Appl. Pyrolysis 2007, 78, 343-362. [CrossRef]

30. Levine, S.E.; Broadbelt, L.J. Detailed mechanistic modeling of high-density polyethylene pyrolysis: Low molecular weight product evolution. Polym. Degrad. Stab. 2009, 94, 810-822. [CrossRef]

31. Roudi, A.M.; Chelliapan, S.; Wan, H.M.W.M.; Kamyab, H. Prediction and Optimization of the Fenton Process for the Treatment of Landfill Leachate Using an Artificial Neural Network. Water 2018, 10, 595. [CrossRef]

32. Roudi, A.; Chelliapan, S.; Kamyab, H.; Md Din, M.F.; Krishnan, S. Removal of COD from landfill leachate by Predication and Evaluation of Multiple Linear Regression (MLR) Model and Fenton process. Egypt. J. Chem. 2019, 62, 1607-1618. [CrossRef]

33. Wallis, M.; Bhatia, S.K. Kinetic study of the thermal degradation of high density polyethylene. Polym. Degrad. Stab. 2006, 91, 1476-1483. [CrossRef]

34. Westerhout, R.W.J.; Waanders, J.; Kuipers, J.A.M.; van Swaaij, W.P.M. Kinetics of the Low-Temperature Pyrolysis of Polyethene, Polypropene, and Polystyrene Modeling, Experimental Determination, and Comparison with Literature Models and Data. Ind. Eng. Chem. Res. 1997, 36, 1955-1964. [CrossRef]

(C) 2020 by the authors. Licensee MDPI, Basel, Switzerland. This article is an open access article distributed under the terms and conditions of the Creative Commons Attribution (CC BY) license (http://creativecommons.org/licenses/by/4.0/). 